\title{
RESET
}

Recherches en sciences sociales sur Internet

4 | 2015

Les mondes du jeu

\section{The online dream of old ludi}

The impact of Vassal and OCTGN worlds on the non-digital gaming in the Italian context

Le rêve en ligne du vieux ludi. L'impact des univers Vassal et OCTGN sur les jeux non digitaux dans le contexte italien

\section{Enrico Gandolfi}

\section{(2) OpenEdition}

\section{Journals}

Electronic version

URL: http://journals.openedition.org/reset/506

DOI: $10.4000 /$ reset.506

ISSN: 2264-6221

\section{Publisher}

Association Recherches en sciences sociales sur Internet

\section{Electronic reference}

Enrico Gandolfi, « The online dream of old ludi », RESET [Online], 4 | 2015, Online since 21 December 2015, connection on 25 April 2019. URL : http://journals.openedition.org/reset/506; DOI : 10.4000/ reset.506

This text was automatically generated on 25 April 2019.

(c) Association Recherches en sciences sociales sur Internet 


\section{The online dream of old ludi}

The impact of Vassal and OCTGN worlds on the non-digital gaming in the Italian context

Le rêve en ligne du vieux ludi. L'impact des univers Vassal et OCTGN sur les jeux non digitaux dans le contexte italien

Enrico Gandolfi

\section{Introduction}

1 Nowadays, digital entertainment is the most important gaming sector in terms of business ${ }^{1}$ and technological innovation. Furthermore, web-portals like Steam, Xbox Live and PlayStation Network provide online platforms able to create new social frames of consumption and affiliation for new as old ludic practices. The digital reformulation of traditional types of games may represent actually an opportunity to enrich and expand hobbies like wargames, boardgames and carding games (etc.). I am not only referring to official portings (e.g., the videogame of Magic: the gathering), but also to a more fragmented scenario often not supported by original producers. This is the case of Vassal and OCTGN: free engines through which thousands of gamers play online famous titles like Carcassone, Warhammer and The settlers of Catan.

2 The aim of this article is to understand how the meaning of the gaming changes according to the switch from non-digital to digital. Thus, we have to consider the social dynamics activated during and because of the play in this new context. Indeed, web places and their increasing flexibility can be interpreted as a critical and communicative environment (Couldry, 2005) with its own laws and consuetudes. Furthermore, web 2.0 logic usually implies militant grounds (forums, social networks, etc.) that permit us to find communitarian feelings and shared habits (Hodkinson, 2011). Regarding the software introduced above, we can imagine analog gaming and its online version as separate sides or instead as converging universes. My main research purpose is to clarify such issue dealing with two perspectives and their possible correlations: the textual ${ }^{2}$ dimension [1] (how does the ludic system change from non-digital to digital?) and the socio-cultural one 
[2] (how do the gaming practice and the related culture change from non-digital to digital?).

In order to answer these questions, I analysed Vassal and OCTGN phenomena in two steps. First, I theoretically explored the manner in which the relation between non-digital system and digital one is articulated with a semiotic and design approach (e.g., Eugeni, 2010; Elias et al., 2012). Second and according to such analytic lens, I investigated the most important communities (forums and websites) in Italy related to Vassal and OCTGN via questionnaires and qualitative interviews; the objective was to test my assumptions and rough out the social environment risen around this software. As touched on above, Vassal is a cross-platform game engine (totally programmed in Java) able to support online adaptations of famous wargames and boardgames with a significant worldwide community; ${ }^{3}$ OCTGN is a similar program even if more specialized in simulating carding games.

\section{The case studies: an overview}

Vassal was released by computer engineer Rodney Kinney in 2003, under LGPL. ${ }^{4}$ A variable group of coders, like Brent Easton and Tim Franklin, frequently updates and refines it with recurrent releases. It can run on many types of hardware and it allows users' interventions due to its Java programming language. It is both a playing engine and an open editor, through which people may add games not still imported or modify the already existent ones: each title can have one or more maintainers, devoted to improving it (in terms of usability, rules, graphics, etc.). This accessibility caused a proliferation of the games translated on and through this software, expanding its libraries; some authors and teams have become famous due to their competence, like Tim Davis and colleagues about the transposition of the famous wargame Warhammer 40k. Usually, the possessor of the related copyright is not the one who brings a specific game system on Vassal. Although we generally observe a sort of institutional indifference or the request of partial limitations, it happens that companies react to the translation of their products: on the one hand, the case of GamesWorkshop (owner of IP like Warhammer, Space Hulk, etc.), which has acted in a legal manner in order to stop this type of activity, is paradigmatic; on the other hand, companies like GMT and District Games give a direct support to the Vassal versions of their products (usually for promotional purposes). The platform is free in its core, but since 2010 authors and producers can follow a low-cost business model in order to charge a fee for some parts of their games. Concerning Vassal's mechanics, a clarifying metaphor is to interpret them as a digital appendage through which players move digital tokens, cards and dices (etc.). There is not any type of artificial intelligence, and the competition is only human versus human (or solitaries, if the rules permit them); thus, it is quite common the use of software like Teamspeaking and Skype in order to communicate with other players. Furthermore, Vassal allows playing in real time, by email and by forum. ${ }^{5}$ The official website offers an official wiki and several forums aimed to improve the synergy and the coordination between players. Specifically, the online experience is filtered via stances (channels), according to the specific title that gamers want to play. In several modules (the digital version of the classic games) the aesthetic quality is adequate, but the overall result strictly depends on the people engaged in its development. 
OCTGN, initially born as Magic emulator and then released in its complete version in 2009, follows a similar operating principle. However, it shows both more limitations to user's modifications and certain restrictions for the available hardware because its programming language is the more closed XML. Anyway, graphical results are generally attractive and some titles work perfectly due to the fans' efforts: carding games like NetRunner and A Game of Thrones (AGOT from the following) are particularly popular on this engine. In the end, users can pay a subscription fee in order to have accessory benefits like in-game sounds, chat images and so on; the aim is to support the official team (lead by the software developer Kelly Elton) in the software improving.

\section{A semiotic overlook}

6 Before entering into the merits of the textual analysis using a design perspective and then an empirical validation, the semiotic approach can support us in setting a preliminary visualization of the game as medium and practice.

7 According to Ricoeur, Eugeni (2010) argues that every experience relies on an interpretation, "a process or a mediation act between two orders of things" (33): 6 the first is the environmental niche that surrounds the subject in sensorial terms; the second is the cultural domain that characterizes and is activated by the user. Within media consumption, we observe a dynamic combination between the two spheres; every experience procures further informational resources for the following one. Indeed, a spiral mechanism takes place in the interpretive process: "it constantly returns on preexistent configurations in order to modify and connect them reciprocally; in this process the same acting of the experience can and often requires to be configured: due to the interpretation, the experience becomes reflexive" (34-35). The experiential planning and the multiplication of intentional objectives specifically connote the media experience; its nature is often serialized and in some way redundant. Moreover, our interaction with media starts from an experiential design, "a projected regulatory activity about some dimensions of ordinary experiences" (43): in a word, media are the devices that try to actualize this plan. Another significant relation is the link between the direct world (the real environment) and the indirect one (the environment built by the medium), possible via the discourse: "the entire and final form gained by sensorial materials responsible of the sensorial access" to the indirect world (44). Such interaction can be:

- Pragmatic: the media experience is perceived in continuity with everyday life;

- Fictional: when we observe an evident distinction between indirect and direct world;

- Aesthetic: the discursive movement gets a particular evidence and fix a relative autonomy from what happens in the indirect world;

- Participative communication: there is a parallelism between discourse and indirect world, which tend to coincide (53).

8 According to Eugeni, media can be persuasive devices, deeply and totally connected to the environment inasmuch as the former dominates the latter (e.g., cinema), or situated ones, which limit their sensorial influence to defined spaces and follow specific times (e.g., iPod) (48-49).Another point is the manner through which media activate and maintain the experience. Concerning this issue, they can be automatic, implying an autonomous operating device, or manual, requiring various types of inputs by the user (49). An extreme case of the latter category is when mind and body work as biological player (e.g., reading a newspaper). 
The media discourse can be explored using two parameters: the first is the opposition between the closeness ("the definition of the discourse") and the openness (the "lack of delimitation") of the media practice; the second one concerns the "discursive movement" through which we experience the medium, which can be unidirectional (e.g., seeing a movie) or follow a reticular and plural structure (e.g., browsing the web) (50-51).

Regarding our topic, we have to understand if games can or cannot be considered media. About such interrogative point, the game designer Koster (2010) argues that ludic systems are not a medium but a peculiar use of a specific medium (loc. 1280). We comprehend better his position using the concept of "cultural medium" proposed by Cosenza (2004), defined as a symbolic domain of cultural grammars and counter-posed to the "technological medium", the technical platform that makes possible the former. Following Eugeni's categories, non-digital games are in the middle between persuasive and situated devices. The cultural dimension of the ludic practices implies that, if the "magic circle" (Huizinga, 1967) works, the game is able to dominate the context. Its evocative and skill-oriented traits increase the immersion in the game world. On the contrary, if the involvement fails, we have a more limited condition.

11 Paradoxically, the digital side of our cases may increase the fragmentation of the experience: screens and multiple programs work as filters, setting a distance between players and the cultural medium. This is in contrast to several asserts by game designers (Brathwaite \& Schreiber, 2009, 216; Schell, 2008, loc. 4553), who remark the importance of an easy and transparent interface. The digital transpositions can try to enrich the graphics to appear engaging, but they are not the natural platform of the titles played. Finally yet importantly, they are complex in comparison to a typical videogame, usually more immediate and accessible. In any case, the active presence of the user is fundamental in order to sustain and trigger the game system: this software needs a sort of digital dexterity, constantly requiring human interventions (to change turns, move, give scores, etc.) due to the absence of AI routines.

\section{The design lens}

12 The semiotic approach gives us an effective analytic start, but it is not enough to cover the peculiarity of the phenomenon explored. Therefore and according to the practitioners' approach, I suggest three dimensions through which trace the dynamics that characterize Vassal and OCTGN and foster their comprehension: the first is systemic, about the game logic and its own mechanics and heuristics; the second is structural, the technical structure that holds up the gaming moment; the third is social and concerns the human interactions that the modification of setting involves. Even if each aspect dialogues with others and affects our research questions (with the technology as median dimension between textual and social issues), this subdivision helps us to figure out how the online version may differ from the physical one.

13 Concerning the systemic dimension, the Game Studies field offers a wide range of models and concepts able to bring to light the in-game mechanics operating during the ludic experience. My intent is to point out specific elements (what I define ludic markers) in order to fix the core identity of the game and then test if it is maintained also within the digital environment. 

fundamental mechanic. They define the space, the objects, the actions, the consequences of the actions, the constraints on the actions, and the goals. In other words, they make possible all the mechanics (...) and add the crucial thing that makes a game a game" (locc. 3068-3102). They can be of several types, among which: operational ("what the players do to play the game"), foundational ("the underlying formal structure of the game"), behavioural ("implicit to gameplay, which most people naturally understand as part of good sportsmanship"), written (on the handbooks/documents with the game) and house ones, when players add and modify original rules creating new patterns and logics (loc. 3074-3088). mean the "rules of thumb that help (...) [gamers] play the game" (29); they may be specific and glaring, or vague and quite abstract. The American designers distinguish between "positional heuristics", about the state of the game (who is winning?), and "directional heuristics", "that tell you what strategy you should follow" (how can we win?) (33).These considerations usually operate combined in a synergic way; they can be clear or more difficult to learn, turn out to be powerful or weak and transversal or specific. From the learning point of view, heuristics are the lesson taught by the game.

The third is the gaming time. Bateman and Boon (2006) propose two main concepts in order to create a common vocabulary about this topic. The first is the "play session length", "a measure of the length of time that a typical instance of playing the game can last" (28); it is subjective and depends on the target that we want to intercept. The second is the "play window", a "theoretical value representing the amount of time a game's audience as a whole spends playing the game" (29); it is the entire life of the game.

The systemic dimension implies further matters: the sensorial/imaginative feelings change (e.g., we cannot touch the tokens, but only see them on the screen), some ludic practices experience a reduction (e.g., the act of painting miniatures disappears) and the skills required are reformulated (e.g., the digital window may alter my perspective). Therefore and according to my research purpose, technology (interpreted as the basic medium in which all gaming elements work together) represents an important topic to analyse. According to Schell (2008), "the technology you choose for your game enables it to do certain things and prohibits it from doing other things." (loc. 1369). We have to identify the technologies that are constitutive, basic to set the experience, and the ones that are decorative and secondary (locc. 7193-7253). Moreover, we must comprehend if and how the technology represents an empowerment or a stop (Meyrowitz, 1993) within the overall ludic experience.

18 As argued by Elias and colleagues (2012), a clarifying parameter is the cost that a game requires in terms of accessibility, an economic but also technological matter. We can have costs that are mandatory (e.g., the price of the mere product) and optional ones functional to improve the quality of the game (e.g., a better PC) (167). Consequently, social skills linked to technical shared frames (forum, chat, etc.) can mean a further barrier of access and domestication (Silverstone \& Hirsch, 1992). As observed by Flanagan (2009), games work as "an ordering logic-a machine, or a technology-for creating social relations, work to distil or abstract the everyday actions of the players into easy-tounderstand instruments where context is defamiliarized just enough to allow Huizinga's magic circle of play to manifest" (loc. 144). The same quality of Vassal modules depends on the effort of its community in terms of play, organization and programming. 
Indeed, concerning the social dimension, Vassal and OCTGN may engage users in these two different ways. Improving the system refers to the so-called "mod culture", whose members manipulate existing videogames for several goals, from fixing them to personal self-expression (Sihvonen, 2011). Anyway, in Vassal and OCTGN cases the community support appears mostly introductive and socially oriented: the access to the software is not immediate and the other players' advice is essential to do the first steps. Furthermore, the lack of an AI entails a strong incentive to find people.

These traits define what Elias and colleagues (2012) call "the metagame", interpreted as "all the activities connected with the game that aren't part of playing the game itself" (203). They consider it the "soft structure" of the play, outside the game but able to affect the ludic consumption. For example, tips and suggestions by other players can drive the gamer and give him further goals to reach, also from a communitarian perspective: gaming status, money, social connections (etc.) (209). This concept is similar to the "gaming capital" described by Consalvo (2007): in short, accounts, skills and knowledge that characterize players outside the game (3).

The rise of the web 2.0 has strongly increased the phenomenon of the virtual communities and consequently of the ludic ones. As observed by Schell (2008), "games are something that inspire real passion in players, so it is not surprising that frequently, communities arise" around them (loc. 6414). Nowadays, the multiplayer side of the digital games is increasingly fundamental, enforced by the social frame that internet is able to guarantee. The web has become a sharing place where feelings of identity and belonging can emerge (Abercrombie \& Longhurst, 1998). Concerning boardgames, Vassal and OCTGN may represent working ways to expand the social halo of this practice exploiting the potential of the online. In addition, the possibility to manipulate the software fosters the participative appeal and facilitates the proliferation of creative communities. To sum up, we can categorize the social activities of a gaming community in:

- Participative: connected to the play and its working.

- Encyclopedia-oriented: focused on sharing information and know-how about the game.

- Social: with the intent is to build and feed social relations.

- Configurative: activities aimed to modify or perfect the game from a technical point of view.

2 These orientations are neither exclusively nor automatically embedded in the game but, according to the Cultural Studies approach (du Gay et al., 1997), they are the result of the interaction between ludic systems, players and the techno-social frames around them; they also may change depending on individuals and communities. The point is to get what types of social efforts and accounts take place within Vassal and OCTGN practices.

Specifically, the intent of my research is to figure out how the first, the second and the third dimension described above change from the original game to its version on Vassal or OCTGN: are the heuristics maintained? How does the technological change affect the ludic experience? Finally, what is the social dimension of this kind of software? I define the ludic translation as the change that a game (as cultural medium) undergoes while getting a new technological setting. We can suppose two main results: the first is the replacing attempt, aimed to reproduce the non-digital experience; the second is the ancillary articulation, with the goal to propose a declination of the original game with a partial autonomy according to the traits of the destination-medium. 


\section{The methodology}

The focus of my research is on the implications of Vassal and OCTGN in systemic and technological terms. Furthermore, I want to understand the social-cultural form that they actualize. Hence, the semiotic perspective must be combined to the analysis of the online communities risen around these platforms (in my case within the Italian context due to the related accessibility). Moreover, this attention permits to test my previous assertions through users' positions about the same topics.

In the beginning, I believed that netnography was the best approach to explore this kind of issue. Indeed, my initial conviction was that the online communities of Vassal and OCTGN had fixed boundaries, a prerequisite for this type of method (Kozinets, 2009).

In the preliminary explorative phase, I have quickly discovered that this is partially true: we are not talking about bulletin boards or forums with a specific and coherent identity. Rather, they are more similar to crossroads, characterized by shared elements but also by an occasional audience. It is quite difficult to establish a Vassal or OCTGN hard culture in the Italian context. It is easier to describe them as a sort of cultural articulation, which expands the availability and the audience of the games translated.

This consideration does not mean a decrease of interest about the phenomenon, but a new calibration of the research instruments: online worlds are still a significant lens in order to analyse and contextualize such digital practices; anyway, they become a specific dimension of the ludic original community and not a totally autonomous one.

This is the reason of a partial change of my methodology, more hybrid and less ethnographic than planned in the beginning. I adopted a qualitative approach (Silverman, 2004) trying to understand the "discursive consciousness" (Giddens, 1984) and the essential narratives (Ricoeur, 1990) of the gamers involved. Therefore, I have done a participant observation, both playing (43 matches, ${ }^{7}$ testing my considerations previously reported and speaking with other players during the matches) ${ }^{8}$ and observing from February to May 2013 the most important related web spaces in Italy with the consensus of their moderators and admins. There were four places of monitoring and recruitment. Concerning Vassal, I focused myself on Giocamici.com ${ }^{9}$ and Advanced Squad Leader (from now ASL) related forum..$^{10}$ The former is the first Italian social network dedicated to Vassal , continually updated about software news and with a specific Teamspeak channel. The latter is the most important online place about $A S L ;{ }^{11}$ it is an exception referring to what I have previously reported: as we will see, VASL (the related module) has consolidated the Italian group of the original game. Dealing with OCTGN, I observed the official forum of AGOT-Italia, ${ }^{12}$ in Italy the most popular game on this platform. In the end, the section about online games of La Tana dei Goblin ${ }^{13}$ forum was a perfect place in order to reach a skilled but flexible audience interested in both platforms. These researching grounds are noteworthy not only for their importance, but also due to their specific peculiarities: each one is paradigmatic indeed, from the focused social network to the product-oriented forum. In the end, I have used a quantitative survey (18 items with fixed answers and 4point unipolar scales) in order to measure the socio-demographic traits of the players and their positions about the topics described above; the aim was to take advantage of the triangulation of methods in order to reach a wide perspective. The replies were 58, mainly from giocamici.com and ASL forum. In total, I have contacted 101 players, 80 from Vassal and 21 from OCTGN. 
cerning my personal gaming background, I was not particularly skilled in boardgames and I did not have any contact with the analysed forums and websites before the exploration. In addition, I never played the games chosen (neither physical material nor digital versions), and I learnt their rules playing 4 non-digital and digital introductive matches for each one (useful also to start the comparison between the two versions) and directly on Vassal and OCTGN platforms. This pre-condition allowed me to be more objective during the research according to a grounded openness (Tarozzi, 2010). However, my competence in related practices and genres (wargames, strategic videogames, tabletop-roleplaying games, etc.) helped me in learning and fixing elements and cornerstones within the ludic systems and the resulting experiences. Moreover, my personal predisposition to complex genres of gaming was precious in setting a common vocabulary with other gamers and fostering the interaction.

\section{The results}

\section{The systemic dimension}

First, game systems seem to preserve their identity after the shift from non-digital status to digital one. For example, Magic is still Magic on OCTGN, and Puertorico is more or less the same thing on Vassal. According to the majority of subjects, from a formal perspective operational and constitutive rules are maintained, even if the former result relatively modified (we need to know the software to be able to play). Thus, heuristics seem to be redundant: "Descent on Vassal is Descent. Maybe it is not perfect and without bugs, but the system (...) is the same" (Piergiorgio); "the main reference is to the original game. I am looking for a symmetrical version of it, not for something different" (Ennio). Consequently, the online version acquires a testing value: users can prove specific gaming strategies and try variants of decks before the physical play. Unsurprisingly, AGOT and Magic are the main titles that benefit from such practice; it is a chance that every player of OCTGN I played with considers essential, also because "the other player can use everything he wants (...) it is a complete and overall challenge" (Massimo). We can interpret is as a way of better accessibility to the entire game potential, in this sector wide for the variety of cards. On Vassal, this possibility is more restricted due to the fact that boardgames cannot be easily expanded; anyway, heuristics are often learnt and refined through this platform. Several members of the online places explored are used to buy the material version of the game first and then have their tutorial on Vassal in order to be more competitive in the non-digital matches. There are numerous forum topics where users admit to be newbie and ask for training plays. Although the play on Vassal and OCTGN seems a sort of systemic gymnasium, players can modify the rules due to the freedom in managing the software. This is particularly evident when there is a continuative group of players. Among friends, house rules may change, even if usually in a marginal way: Claudio admits that "sometimes it happens. But it is more for fun than for really improving the session". In addition, Fulvio states that "If all we agree, it is possible to change some secondary rules. A sort of gaming experiment, do you know? But the results are often hilarious". This creativity is rarer playing with strangers instead, and behavioural rules (avoiding every cheating, being assertive with other players, etc.) become the priority in order to preserve the fairness during the game: a reaction to the absence of an AI, which usually works also as judge in the other types of online gaming.

RESET, 4 | 2015 
31 Regarding the game time, the rhythm of the play seems to change. Vassal and OCTGN allow plays by e-mail, by forum and in real time, and even in the third modality the technological filter seems to protract the duration of the game: "there is a dilation of time. It is good because in the end you can freeze the game and think about our strategies, however you lose something in terms of concentration (...) there is less adrenaline" (Fabio); "more relaxing to the detriment of the intensity (...) but we work all day, we have family, and it is hard to find another way to play" (Piergiorgio); "my free time is quite variable, so Vassal allows me to manage it easily. I would not be able to do that with traditional plays" (Stefano); "I still play boardgames of 5, 10 years ago on Vassal, games whose packages are lost in my library" (Renzo). Consequently, Vassal and OCTGN play session length is usually longer than the traditional one; however, the overall play window of the former benefits from the managing control (e.g., stop and save the match) given by the software.

To sum up, we observe a strong fidelity to the original products on Vassal and OCTGN. In some way, players are the gatekeepers of the constitutive rules. This is particularly true for titles like Warhammer and Heart of Iron that are more wargames than boardgames: a type of games characterized by complex systems and dense backgrounds, hard to reproduce on the screen. Unsurprisingly, the majority of users are intensely involved in Vassal modules due to their core fidelity to the source games: someone in a way similar to the non-digital versions (31\%), someone else in a different manner but with a comparable intensity (54\%).

\section{The technological dimension}

Regarding the technical issues of Vassal and OCTGN, the evolution is more relevant. About the learning phase (the new operational rules), users usually describe the software mechanics as "easy to learn" or "neither easy nor hard to learn". Moreover, the wide amount of tutorials and guides (the written rules available on the web) supports the new gamers. Therefore, the apparent inaccessibility of Vassal results in a superficial fear, due to the multiple screens of the main interface. As I personally tested, after few matches the modus operandi becomes clear and quite intuitive. In a word, the learning cost of the new technology is insignificant. Furthermore, if we consider the price of packaged games and competitive decks, the online gaming can represent a precious source of saving. Especially Vassal provides a good occasion to try a game before the purchase: "if there is the Vassal version of a product that I want to buy, I play it to get a sense of the game and possibly to spend my money wisely" (Tito). Then, I have heard many complaints about the saturation of products in boardgame market, and online platforms work as a filter to facilitate a more conscious consumption. According to the quantitative survey, the more numerous groups of users are wargamers and addicted boardgamers, targets characterized by a relevant collecting desire.

From a technological point of view, the advantages of the digital context are evident. According to my subjects, the more appealing traits are the long-distance plays, the feature of saving matches, the platform versatility and the ability to simulate a wide range of games. The worst ones remain the overall graphic, the scarcity of audio support, the technical bugs and the slowness of the system itself. By the way, it is recurrent a justifying attitude due to the open-source philosophy of the project: "we are talking about an open project, not a program with a dedicated programming like a videogame (...) 
it is not fault of Vassal" (Vittorio). Linked to this point, one problem is that "when a new version is published, often the parallel one on Vassal is not updated" (Carmine): it depends on the reaction of the community and on the productive strategy. Moreover, old saves are often incompatible with new releases of the software. OCTGN is more appreciated for its graphic aspect, although the ludic domain it is able to cover is significantly restricted.

There is a strong heterogeneity of positions about the absence of physical elements. For some players it is a "heavy lack"; for others this condition helps the focus on the game system. According to wargamers interviewed, the problem is also a visual matter (the "positional heuristics"): the comprehension of what is happening is easier with a large desk full of miniatures than using a PC with a limited screen. Furthermore, for almost all the material components are a fundamental part of the hobby. The aesthetic beauty of some pieces and the ownership pleasure are strong drivers in gaming practice and consumption: "in VASL the appeal of the package, the unboxing ritual (etc.) are absent (...) Vassal is a perfect palliative, nothing more" (Ennio); "the physical game has a value" (Fabio); "I will never spend money for the online version" (Marco). For wargamers, whose passion results articulated (from painting miniatures to the historical research, activities usually absent in boardgaming), this issue is particularly true. Playing I have met several wargamers who use Vassal to have a break with boardgames. Enzo argues that "Vassal is perfect if you want pass the time with simple games (...). But when I have to use it for wargames, and it is terrible. The ludic feeling is totally absent". In addition, Remo observes that "it does not matter how much good is the module, I cannot touch or paint my army (...) my army does not exist at all". By the way, other wargamers admit that Vassal saves them from the logistical requirements that characterize their hobby (large spaces, long setup phase, a significant amount of game pieces to carry, etc.).

The absence of face-to-face interaction is another predicable defect: "I may appear a little bit fetishist, but keeping in your hand counters, hearing the rolling of the dices and looking at my friend's eyes are something different [in comparison with Vassal experience]!" (Carmine); "the pleasure of physical materials and the contact with your opponent, seeing his reactions and kidding him, make live experiences superior" (Arnaldo).

37 In the end, the fidelity to the original game is reproduced from a technical perspective, as well. Few subjects play Vassal and OCTGN modules in a univocal way ${ }^{14}$ and no one sees them as libraries of free games able to replace the original titles. Returning to Eugeni, the experience on these engines is neither aesthetic nor fictional, but more participative and pragmatic. This software solves specific problems in continuity with the non-digital practice renouncing to an immersive and autonomous engagement.

\section{The social dimension}

Concerning both Vassal and OCTGN, the forum is the most important type of online hangout. The overall average of daily active users is from 9 to 14 , with a sporadic presence of a bigger number of visitors. La Tana dei Goblin is more popular than other forums due to its fame in the Italian context. The usual modalities to approach for the first time these platforms are the specialized websites on boardgames and following the friends' advices. On Vassal the age is quite high, usually from 40 to 45 years old (especially wargamers and VASL users) and from 35 to 40 (referring to boardgamers). The OCTGN 
gamers are younger, usually from 25 to 30 years old. This result is symmetrical to the targets of the non-digital products (Magic was born in 90's and AGOT ten years later). The shift from Vassal to OCTGN and vice versa is uncommon (2\%). Players who I have met are addicted users (one or more matches weekly) or occasional ones (one play every two weeks or every month), rarely someone in between. They started to use the software mostly in 2010 (39\%) and 2011 (49\%). This consumption frequency is repeated in the nondigital practice: Vassal-OCTGN gamers are active players and fans of the original games; the $53 \%$ is member of associations and clubs of boardgamers and wargamers.

Close groups of gamers are frequent, but usually strictly within the online practice. In a word, in my exploration I have found only two assembles of friends that play both online and face-to-face. The Vassal/OCTGN-oriented groups, born and develop among these platforms, result more common: "I have my stable group of players on Vassal, step by step we have become friends" (Remo). Other users are used to play with people known on related forums, strangers and old friends. The opportunity to vie with distant contacts is an important feature for some Vassal users: a sort of ludic bridge able to maintain friendships that are demanding in everyday life: "I have rescued old friends through Vassal. It sounds cold, but anyway it is a manner to stay in touch" (Francesco). Instead, OCTGN players appear more competitive and focused on the game itself; some of them complain about the absence of skilled opponents.

According to what written above, strategies and tactics learnt online are discussed with other Vassal players, and more rarely with players not accustomed to this software: "it is hard to talk about Vassal if your interlocutor does not know it: gaming aspects and technical issues are often mixed" (Fulvio). On the contrary, OCTGN is seen more as an instrumental device without a cultural sphere, and its users directly report to their livegame friends "better decks and strategies, it is quite automatic" (Damiano).

41 During the ludic sessions, players remark the tendency to talk about everything. Anyway, for someone this is not a good thing: "using Skype and also speaking a good English, I usually discuss a lot of things, just to be polite (...) but in this way the game becomes too long" (Marco). Hence, some gaming groups are rigorous in talking exclusively about the match while they are playing: "when we talk, we talk. When we play, we play. It is our habit" (Enzo).

To sum up, Vassal and OCTGN forums work as services and connective places. Their functions are basically three:

- To find people and organize matches. However, private channels (e.g., by e-mail) are the most important method to arrange the play.

- To ask for help and advices about software and gaming.

- To share contents (tips, gaming stories, etc.).

The first and second activities are common in every online place I explored (they concern the $80-90 \%$ of the topics). The third (propaedeutic to a cultural reinforcement) is rarer, depending on the role of the software in the specific gaming context. Referring to ASL, this calling represents a fundamental dimension due to the historical connection between such title and the engine, whereas for other games is more a secondary feature. Generally, discussions are correct and polite, with a glaring respect of the netiquette: every question is answered quickly and with courteousness. The creative efforts remain marginal in the places observed. The main engagement is in translation issues, usually from English to Italian language. Two persons I listened to have created specific scripts 
for the roll of the dices in order to prevent sabotages and cheats, but I am talking about an exception. The situation does not change with videos of plays updated on Youtube (etc.), usually viewed but not created.

To conclude, social dynamics on Vassal and OCTGN forums are strictly participative and encyclopaedia-oriented (with a relevant accessibility intent). Regarding the former, they can represent a starting point to build a gaming group then kept through private channels. The latter is more competitive instead, due to its specific focus on challenging and the significant boundary with live-friends. In the end, the creative activities are almost absent and without a collective dimension.

\section{Conclusions}

From a textual point of view (answering the first research question [1]), the gaming on Vassal and OCTGN seems to maintain its own identity in comparison to its non-digital origin. Although there are several changes in terms of experience due to the technological switch, we are talking about a replacing attempt that tries to solve the problems of the packaged versions. Vassal and OCTGN users usually admit that they are playing a "satellite version", a reduction of the physical game. However, the digital setting seems to improve the reasoning and the concentration during the play. The absence of face-to-face interaction restrains the experiential sharing with other people, and the potential of immersion remains poor because the software is rudimentary. Thus, the better focus on the pure gameplay makes users more rational in analysing the game session: "on Vassal we may test the last version quickly (...) and playing with strangers is more (...) you know, neutral and objective" (Luigi); "the possibility to have this kind of variety [on OCTGN] in terms of cards permits you to have a better comprehension of the patterns" (Marco); "no graphics, no sounds, no distractions, only mechanisms" (Giorgio). Unsurprisingly, even if it is possible to find some gaming stories on forums, usually battle reports about Vassal and OCTGN are analytic and schematic bulletins of moves and counter-moves.

If one adopts a socio-cultural perspective (answering the second research question [2]), the result is different. As I reported above, the online dimension implied by the software strongly affects the timing of sociality and the gaming relations. Many Vassal users ${ }^{15}$ underline the presence of a community of practice regarding the activity on this platform: social contacts less significant (with the exception of VASL) and that anyway are similar to the ones embodied by the original game. We can interpret it as a soft articulation: the destination medium, even though the gaming partners may be different, maintains the culture of the previous one and represents a sort of appendix. Subjects interviewed feel to belong to a shared game culture, in continuity with the non-digital origins and different from the topoi of digital games, which have in common only the technological medium: "people on Vassal are very similar to the friends I play with" (Stefano); "we are all gamers" (Enzo); "we try to revitalize real games, not to follow the digital entertainment trends" (Martino). It is a soft but diffused relationship, with few strong social coagulations and a service-oriented use of the forums. To sum up, the digital setting implies a secondary (for importance) but denser (for further technological rules and logics) "gaming capital", which can entail new gaming interactions. The apparent inaccessibility of Vassal and OCTGN works as a filter in order to keep away who is not keen about non-digital games: "if you want to play Vassal, you have to persevere (...) just a 
little, but enough to scare who is not really interested" (Ennio). Unsurprisingly, the majority of Vassal players I interviewed (82\%) neither play nor like videogames, even though they are enthusiastic wargamers and boardgamers. Thus, it is possible to observe how traditional feelings of belonging are fuelled by new technologies: "we are not a real community (...) but I think we have a common origin, a shared sensibility, in Italy as in Spain" (Diego); "ASL is more a community than Vassal (...) by the way, there is something that connects us" (Andrea). The reference is to a sort of imagined gaming nation (in the terms of Anderson, 1983), concretely experienced with both live friends and Vassal ones but generally characterized by an abstract and fluid status. Other Vassal players are described as "polite", "expert", "cool", "erudite", "beautiful people", "skilled", "passionate" and "smart". Moreover, everyone is proud to describe the overall Vassal community as close in "excluding cheaters and trolls, and following the absolute respect of the rules" (Vittorio). During playing and on online places, the interactions are often polite and friendly. The social cost of the new digital environment is insignificant indeed, because its social accounts and standards are in some way known and derived from a previous and familiar context, the original gaming one: a culture defined as "passionate", "open-minded" and "fair". OCTGN landscape is more neutral and less connoted, with a well-established competitive attitude. Its users do not show a shared perception of an old community. In a word, "it is a tool to improve yourself, nothing more" (Luca).

In the end, Vassal and OCTGN transpositions remain loyal to their non-digital origins, in terms of mechanics and systemic identity: from a textual point of view, we assist to a replacing attempt. Indeed, in the Italian context this software is managed by social web structures that follow pragmatic and participative priorities. However, its users show a strong feeling of communion and belonging to the ethics of play. We can interpret it as a specific and ancillary articulation of their traditional game culture, a statement able to evoke an imagined community empowered by the coherent dynamics of Vassal and OCTGN phenomena.

\section{BIBLIOGRAPHY}

ABERCROMBIE Nicholas \& LONGHURST Brian (1998). Audiences: a sociological theory of performance and imagination, London, Sage.

ANDERSON Benedict (1983). Imagined communities: reflections on the origins of nationalism, London, Verso.

BATEMAN Chris \& BOON Richard (2006). 21st century game design, Hingham, Charles River Media. BRATHWAITE Brenda \& SCHREIBER Ian (2009). Challenges for game designers, Boston, Cengage Learning. CONSALVo Mia (2007). Cheating: gaining advantage in videogames, Cambridge, The MIT Press. CoSENZA Giovanna (2004). Semiotica dewe refnuovi media, Rome, Laterza. 
COULDRY Nick (2005) « The extended audience: scanning the horizon », in Gillespie Marie (ed.) Media audiences, Maidenhead, Open University Press, pp. 183-222.

DU GAY Paul, HALl Stuart, JANES Linda, MACKAY Hugh \& NEGUS Keith (1997). Doing cultural studies. The story of the Sony Walkman, London, Sage/The Open University.

ECO Umberto (1975). Trattato di semiotica generale, Milan, Bompiani.

ELIAS George Skaff, GARFIELD Richard \& GUTSCHERA K. Robert (2012). Characteristics of games, Cambridge, The MIT Press.

EUGENI Ruggero (2010). Semiotica dei Media, Rome, Carocci.

FLANAGAN Mary (2009). Critical play: radical game design, Cambridge, The MIT Press.

GIDDENS Anthony (1984). The constitution of society, Cambridge, Polity Press.

HODKINSON Paul (2011). Media, culture and society: an introduction, London, Sage.

HUIZINGA Johan (1967). Homo ludens, Milan, Il Saggiatore [1938].

KOSTER Raph (2010). A theory of fun for game design, Sebastopol, Paraglyph Press [2004].

KOZINETS V. Robert (2009). Netnography: doing ethnographic research online, London, Sage.

MÄYRÄ Frans (2008). An introduction to game studies, London, Sage.

MEYROWITZ Joshua (1993). Oltre il senso del luogo: come i media elettronici influenzano il comportamento sociale, Bologna, Baskerville [1985].

RICOEUR Paul (1990). Soi-mème comme un autre, Paris, Les éditions du Seuil.

SCHELL Jesse (2008). The art of game design: a book of lenses, Boca Raton, CRC Press.

SIHVONEN Tanja (2011). Players unleashed!, Amsterdam, Amsterdam University Press.

SILVERMAN David (2004). Qualitative research: theory, method and practice, London, Sage.

SILVERSTONE Roger \& HIRSCH Eric (1992). Consuming Technologies: Media and information in domestic spaces, London, Routledge.

TAROzzI Massimiliano (2010). Che cos'è la grounded theory, Rome, Carocci [2008].

\section{NOTES}

1. According to Gartner data, the global videogame industry has generated 93 billion of dollar in 2013.

2. I adopt an extended definition of "text" as practice and focalized interpretation as suggested by Eco (1975)

3. If we observe the official server status (available at http://www.vassalengine.org/ status.php), there are 50.000-55.000 monthly users.

4. Acronym of Lesser General Public License (for more information see http:// www.fsf.org).

5. In the second and in the third case, players communicate their moves by e-mails and posts on forum.

6. The translation from Italian to English of Eugeni and the subjects interviewed is by the author. 7. 32 on Vassal and 11 on OCTGN. About the former, the games proven were Carcassonne, Descent and ASL (due to their diffusion), the latter was used for AGOT. The players I 
challenged with were all Italian and partially from the online places analyzed. The names used are pseudonyms in order to protect their anonymity.

8. A sort of ludic interview, performed during the gaming session. This situation has often helped the emersion of ideas and positions by subjects because the ludic practice is both the framing activity and the research object of the analysis. In a word, often it happened a sort of practical reflexivity during the play itself.

9. www.giocamici.com

10. freeforumzone.leonardo.it/forum.aspx? $\mathrm{c}=33105 \& \mathrm{f}=33105$. The overall forum has 274 members, and the specific section about the online 191 discussions and 1126 posts (last visit: $17^{\text {th }}$ June 2013).

11. The game that gave the inspiration to the creation of Vassal and whose online version is still popular in Italy and worldwide.

12. www.agameofthrones.it. The overall forum has 701 members, and the specific section about the online gaming 68 discussions and 1475 posts (last visit: 17 $7^{\text {th }}$ June 2013).

13. The first ludic Italian association (from boardgames to tabletop RPGs) in terms of activities and resources (www.goblins.net). The specific section of the forum about the online gaming (concerning our cases but also other software) has 524 discussions and 10900 posts (last visit: $17^{\text {th }}$ June 2013).

14. Anyway, for some niche products like ASL, "Vassal is the only way to play with regularity" (Stefano), or, for more unlucky cases, "to play a game no more in production" (Carmine).

15. OCTGN gamers are more reluctant about a possible OCTGN culture.

\section{ABSTRACTS}

The article focuses on the Italian game culture risen around Vassal and OCTGN - i.e., free online engines through which thousands of gamers play every day physical boardgames and wargames like Carcassone, Warhammer and The settlers of Catan. Specifically, the analysis addresses how the relation between this specific digital play and its material origin is articulated in terms of game system/practice and social environment. Accordingly, a framework that takes into account suggestions from Semiotics, Game Studies and Sociology was applied to empirically assess the concrete environments generated by these tools. Observation of related online forums $(n: 4)$ was conducted and participant involvement in several matches (n: 43) was staged; finally, a survey was distributed among expert gamers (n: 58). Results show that Vassal/OCTGN culture is a soft articulation of the boardgame/wargame one: albeit the glaring differences in the media experience per se, subjects stated that these programs entail an articulation of their physical ludic hobby rather than a new and autonomous passion.

L'article se concentre sur la culture ludique italienne formée autour de Vassal et OCTGN, c'est-àdire des moteurs gratuits en ligne grâce auxquels des milliers de personnes jouent quotidiennement à des jeux de plateau IRL et des wargames comme Carcassone, Warhammer et The Settlers of Catan. Plus précisément, cette contribution étudie la façon dont la relation entre les jeux numériques et leurs origines matérielles est articulée en termes de système/pratique du jeu 
et d'environnement social. En conséquence, nous avons fait usage de notions empruntées à la sémiotique, aux game studies et et à la sociologie afin d'évaluer de manière empirique les environnements concrets qui étaient générés par ces outils. Nous avons procédé à l'observation de forums et nous sommes impliqués dans plusieurs matchs ; enfin, un questionnaire a été distribué à des joueurs experts. Les résultats de nos recherches montrent une articulation entre les cultures Vassal/OCTGN et les jeux de plateau/wargames. Malgré les différences dans l'expérience du média, les acteurs ont déclaré que ces programmes engendraient une articulation entre leur hobby ludique IRL plutôt qu'une passion nouvelle et autonome.

\section{INDEX}

Keywords: ludic communities, OCTGN, online gaming, Sociology of Culture, triangulation of methods, Vassal

Mots-clés: communautés ludiques, OCTGN, jeux en ligne, sociologie de la culture, triangulation ddes methods, Vassal

\section{AUTHOR}

\section{ENRICO GANDOLFI}

Kent State University, Research Center for Educational Technology 